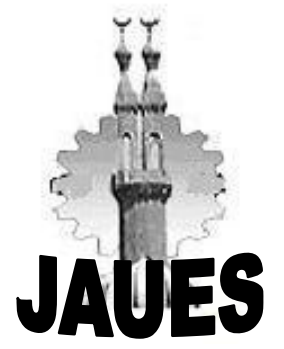

Journal of Al Azhar University Engineering Sector

Vol. 13, No. 49, October, 2018, 864-871

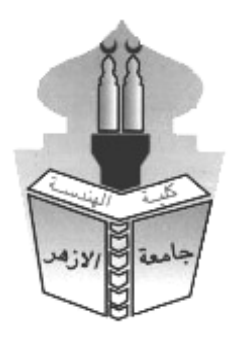

\title{
FLOW MODELLING AND PERFORMANCE ASSESSMENT OF ROTARY SLIDING VANE PUMP USING COMPUTATIONAL FLUID DYNAMICS
}

\author{
Mohammed Akmal M. Ammar, Nabil A. Mahmoud, Ahmed R. El-Baz \\ and Ashraf M. H amed \\ Mechanical Power Eng. Dept. Faculty of Engineering - Ain Shams University, Cairo , Egypt
}

\begin{abstract}
A pump is a mechanical device that converts mechanical energy into hydraulic energy. The aim of the current work is to examine the behavior of fluid flow inside a rotary sliding vane pump and assessing the performance by studying the effect of change of the rotational speed, number of vanes and the radial clearance gap size between vane tips and stator surface on the performance of the pump. The commercial finite-volume solver ANSYS Fluent was used to simulate flow behavior in the pump with an additional $\mathrm{C}$ source code for the description of the dynamic mesh motion. Pump flow has been studied using lubricating oil, 5W-30, as the working fluid. Several computational configurations were used for the numerical simulation. The numerical results showed that $100 \%$ increase of the number vanes decreases the overall efficiency by $46.5 \%$, while increasing the clearance gap size from 0.025 to 0.05 decreases the overall efficiency by $9.72 \%$, and results in a $42.85 \%$ increase in the internal leakage within the pump.
\end{abstract}

Keywords : CFD, Turbomachines, Positive-displacement, Sliding, Vane pump

\section{Nomenclature}

D Diameter

BP Input driving brake power

$\mathrm{k} \quad$ Turbulent kinetic energy

$\mathrm{m}^{\circ} \quad$ Mass flow rate

$\mathrm{N} \quad$ Pump rotor rotational speed

$\Delta \mathrm{p} \quad$ Pressure difference across pump

$\mathrm{Q}_{\text {th. }} \quad$ Theoretical volume flow rate

Q Volume flow rate

$\mathrm{T}_{\mathrm{av}}$ Time-averaged torque acting on

g. rotor

$\Delta \mathrm{t} \quad$ Time step size

\section{Greek Letters}

m $\quad \varepsilon \quad$ Rate of kinetic energy dissipation $\mathrm{m}^{2} / \mathrm{s}$

Watt $\eta \quad$ Overall pump efficiency $\%$

$\mathrm{m}^{2} / \mathrm{s}^{2} \quad \omega \quad$ Angular velocity of rotor $\mathrm{rad} / \mathrm{s}$

$\mathrm{Kg} / \mathrm{s}$ Abbreviations

rpm CFD Computational Fluid Dynamics

$\mathrm{N} / \mathrm{m}^{2}$ NAC National Advisory Committee for A Aeronautics

$\mathrm{m}^{3} / \mathrm{s} \quad$ UDF User-Defined Function

$\mathrm{m}^{3} / \mathrm{s}$

N.m

S 


\section{INTRODUCTION}

Rotary sliding vane pumps consist of a radially slotted rotor which is eccentrically placed in a stationary body (usually called a stator). The rotor is located close to the wall of the stator so that a crescent-shaped cavity, which is responsible for the compression action, is formed. The rotor is sealed from the stator by two side plates. Vanes or blades fit within the slots of the rotor along its axis. As the rotor rotates and fluid enters the pump due to the suction effect. During rotation centrifugal force push the vanes to the walls of the stator. The tight seal among the vanes, rotor, stator, and side plates is essential to achieve the good suction characteristics of the vane pump. Ramelli is credited with the invention of rotary sliding vane pumps in the $16^{\text {th }}$ century [1].

Vane geometry has a considerable effect on the condition of lubrication between the tips of each vane of a vane pump and stator. It was concluded in the research of Elashmawy and Alghamdi [2] that vane tip radius of curvature should not be less than $2 \mathrm{~mm}$ and recommended to be higher than $3 \mathrm{~mm}$, to enhance the lubricating conditions. In general, increasing vane thickness decreases vane tip friction coefficient at low temperatures. Moreover, at an operating pressure of $200 \mathrm{bar}$, the minimum vane thickness of straight vane geometry was $1.3 \mathrm{~mm}$ with maximum vane deflection of $12 \mu \mathrm{m}$. While the minimum vane thickness value of $2.4 \mathrm{~mm}$ and $3.0 \mathrm{~mm}$ with maximum vane deflection of $18.5 \mu \mathrm{m}$ and $18.1 \mu \mathrm{m}$ were obtained for forward and backward curved vane geometry.

Flow between the vanes and the stator was studied by Lisowski and Panek [3]. They showed that choice of the suitable contact force of the vanes against the stator along with choosing proper pump geometry have a significant influence on achieving high efficiency and life of the pump. This research was performed using CFD for three different types of vane pumps, each having different vane tip geometry: R4 radius tip, Double blade profile tip, and NACA 4510 tip. Both velocity and pressure contours were examined to gain some knowledge on the leakage behavior at the vane tip for each vane tip geometry. The analysis also included study of turbulence generated within the chamber. They found that turbulence is generated for rounded tip. Minimum flow rate and thus leakage was achieved using the NACA type tip profile. The NACA profile also provided the smallest radial and tangential forces against the stator.

Cavitation flow in sliding vane pumps was studied by Würtenberger [4] using a twodimensional model. It was found that the flow-limiting effect of cavitation usually sets in at a pump speed level lower than desired and is accompanied by detrimental effects. Therefore, it is imperative to determine the critical pump speed at which the flow-limiting effect becomes evident. A mathematical parametric study on the most crucial design parameters of a rotary sliding vane pump of the variable displacement type was reported by Babu et al. [5]. They showed that the vane geometric parameters are the most important part and the most critical parameter of the pump assembly. These are namely, vane thickness, number of vanes, vane width, and length. Meece et al. [6] studied design factors of sliding vane pumps and concluded that recommended factors are as follows (see Fig. 1): $\mathrm{r} / \mathrm{R}=0.8 \sim 0.9$, e/ $\mathrm{R}=0.2$ (for low pressure values) and $\mathrm{e} / \mathrm{R}=0.1$ (for high pressure values). Moreover, the maximum recommended vane tip surface speed was found to be $12 \mathrm{~m} / \mathrm{s}$. In addition, it was concluded that number of vanes are selected according to displacement and pressure differential acting on them.

Performance characteristics of a variable displacement rotary sliding vane pump were studied by $\mathrm{Oh}$ et al. [8]. It was concluded that discharge flow rate and pressure variations within the pump increased with the increase of the pump rotor rotational speed. Moreover, the results have shown that as the temperature of the working fluid increase, the discharge flow rate and driving torque decreases. In addition, cavitation has occurred at low temperature of the working fluid and higher rotational speed of the pump rotor.

Erosion and cavitation damage due to surface protrusions have been the subject of investigation of Peng, Chem, et al. [9]. The researchers have used numerical analysis using the Reynolds-Averaged Navier-Stokes (RANS) equations for different values of protrusion sizes. They have concluded that even the tiniest of protrusions on vanes surfaces can cause the static 
pressure to reach levels below the vapor pressure of the water which they have used as the working fluid.

Experimental techniques along with verification by analytical modelling have been used by Emiliano and Alessanfro, et al. [10], in order to gain more knowledge regarding the effect of proper lubrication between vane tips and the inner surface of pressure rings. The researchers' methodology has used the basis of Archard's law and an empirical model for the estimation of contact pressure forces and hardness standard tests. Analysis of the results has shown that low wear and reduced friction can be obtained if elasto-hydrodynamic lubrication between vanes and pressure ring is established.

Power steering of vehicles widely incorporates the use of vane pumps. This application has been experimentally investigated by Kim and Bae, at al. [11]. They have shown that variable displacement vane pumps are possible to improve the fuel economy by varying the pump capacity with a vane mechanism according to the engine operating speed range and reducing its driving torque.

Pressure and flow ripples of variable displacement vane pumps with a pressure compensator were theoretically analyzed by numerical calculations in work of Ueno and Shentai, et al. [12]. It has been proven that the leakages due to a fluid compressibility definitely affect the ripples of pressure and flow of both compression and expansion processes of a confined displacement chamber

It can be found from literature that more work should be dedicated for the purpose of better understanding of rotary sliding vane pumps using numerical techniques, since these techniques can provide in-depth, closer look at flow behaviour at different operational conditions. Numerical computer simulation results are presented at various values of design parameters which are the rotational speed, number of vanes and the clearance gap size between vanes tips and stator inner surface.

\section{Methodology}

\subsection{Design Parameters of Rotary Sliding Vane Pumps}

The basic geometry of rotary sliding vane pump is shown in Fig. 1. The pump rotor has radial slots inside which the sliding vanes are inserted. Due to the eccentric position of the rotor relative to the stator, a crescent shape is formed and vane length in contact with the pumped fluid varies as the vanes rotate with the rotor. Once the vane passes the suction port fluid pressure in the trapped volume between two successive vanes starts to increase. The pressure build up onside this cavity reaches the discharge pressure once the leading vane reaches the discharge port. 


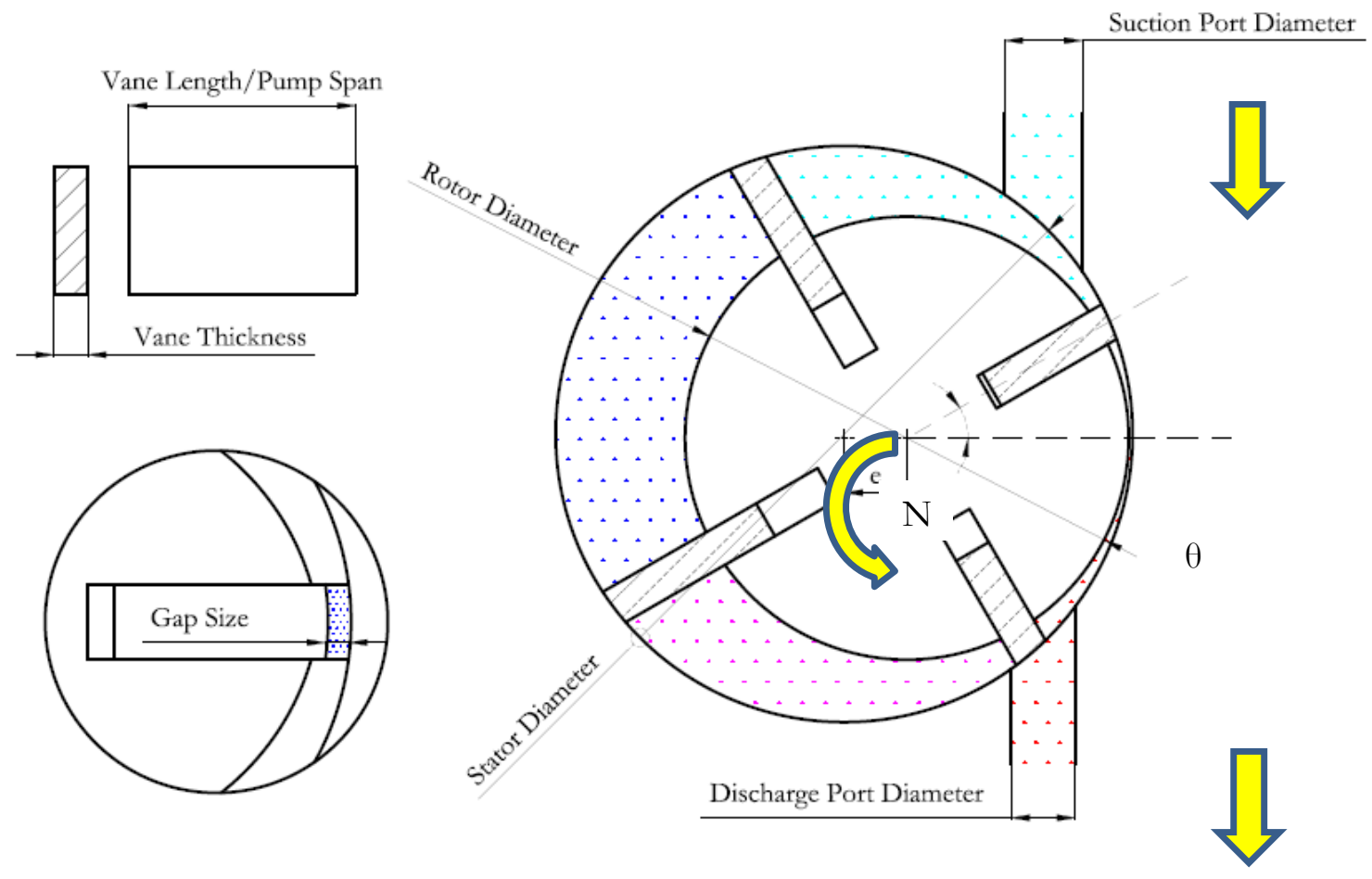

The design

Fig. 1: Main Dimensions of a Typical Rotary Sliding Vane Pump

dimensions which were used in the current study are shown in Table 1.

Table 1: Design Dimensions of the Rotary Sliding Vane Pump, [7]

\begin{tabular}{|l|c|}
\hline Stator Diameter $\mathrm{D}_{1}(\mathrm{~mm})$ & 55 \\
\hline Rotor Diameter $\mathrm{D}_{2}(\mathrm{~mm})$ & 50 \\
\hline Suction Port Diameter $(\mathrm{mm})$ & 12 \\
\hline Outlet Port Diameter $(\mathrm{mm})$ & 10 \\
\hline Eccentricity (mm) & 2 \\
\hline Vane Thickness (mm) & 3.5 \\
\hline Vane Length (mm) & 25 \\
\hline Gap Size (mm) & 0.075 \\
\hline
\end{tabular}

Theoretical volume flow rate through the sliding vane pump is calculated as:

$$
\mathrm{Q}_{\text {th. }}=\pi / 2\left(\mathrm{D}_{1}+\mathrm{D}_{2}\right) \text { e } \mathrm{L} \mathrm{N} / 60 \quad\left(\mathrm{~m}^{3} / \mathrm{s}\right)
$$

where $\mathrm{Q}_{\text {th. }}$ is the theoretical volume flow rate of the pump, $\mathrm{D}_{1}$ is the stator diameter, $\mathrm{D}_{2}$ is the rotor diameter, $\mathrm{e}$ is the eccentricity of the pump, $\mathrm{L}$ is the pump span which is also equivalent to 
the vane length, $\mathrm{N}$ is the rotational speed of the pump rotor in rpm. It should be noted that the above-mentioned design values are all within the recommended range provided in the work of Meece et al. [6].

\subsection{Operating Parameters}

Performance of a rotary sliding vane pump can be assessed by observing the input torque for driving the pump and the volume flow rate, for a specified pressure rise. Using these parameters, other performance factors can be obtained such as: required power to drive the rotary sliding vane pump, the fluid power and the rotary sliding vane pump overall efficiency, using the following relations:

$\begin{array}{ll}\text { Brake Power }=\mathrm{T}_{\text {avg. }} \times \omega & \text { (Watt) } \\ \text { Fluid Power }=\Delta \mathrm{p} \times \mathrm{Q} & \text { (Watt) } \\ \text { Overall Efficiency }=\text { Fluid Power/Brake } & (\%) \\ \text { Power } & \end{array}$

where $T_{\text {avg. }}$ is the time-averaged torque acting on the pump rotor, $\omega$ is the angular velocity of the pump rotor, $\Delta \mathrm{p}$ pressure difference across the rotary sliding vane pump $=$ discharge pressure suction pressure, $\mathrm{Q}$ is the volumetric flow rate of the pump.

\subsection{Rotary Sliding Vane Pump Numerical Model}

In the present study the three dimensional finite volume CFD program ANSYS-FLUENT was used to solve the Reynolds averaged mass and momentum conservation turbulent flow equations for the sliding vane pump. The equations were solved using a dynamic mesh model which considers the deforming nature of the control volumes within the gap between pump rotor and stator as the pump vanes rotate. A User Defined Function [7] (UDF) C source code for the description of the dynamic mesh motion was applied. Three different models were constructed for four, six and eight vanes pump. The numerical model for the eight-vane pump is shown in Fig. 2. The pump geometries are identical except for the number of vanes installed in each one.

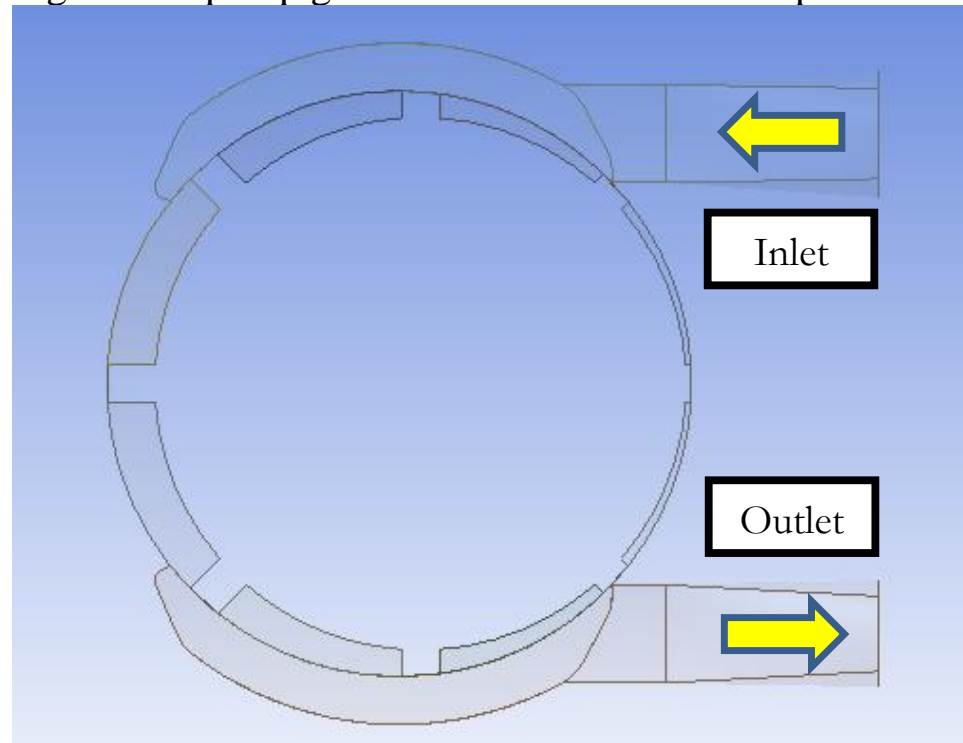

(a)

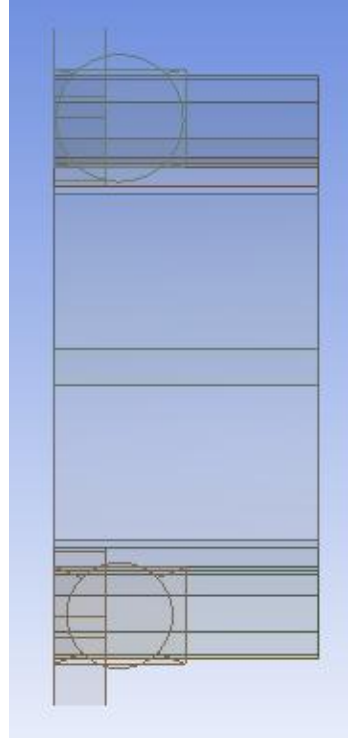

(b)

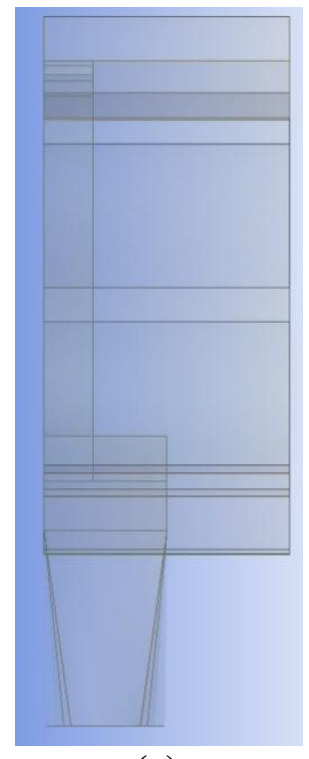

(c)

Fig. 2: Eight-Vane Rotary Sliding Vane Pump Numerical Model (a) Elevation View (b) Side View (c) Plan View 
The grid independency test has been performed at 0 bar gauge suction pressure at inlet and 20 bar gauge discharge pressure at outlet. Turbulent intensity at inlet was set to 5\%. All stationary surfaces and blade surfaces are defined as "wall", having a no-slip condition with a constant wall roughness value of 0.5 . Surfaces that move relative to other surfaces are defined as "interface", as per the recommendations in [7], as shown in Fig. 3.

The standard k-epsilon turbulent model with standard wall functions was used to model turbulence effects. In addition, the pressure-velocity coupling scheme PISO was used with the gradient special discretization method is Least Squared Cell Based. Second order upwind discretization method was used for momentum and turbulent kinetic energy Moreover, the transient formulation scheme is First Order Implicit, the absolute criteria value for the equations residuals of momentum, $\mathrm{x}$-velocity, y-velocity, z-velocity, $\mathrm{k}$ and epsilon is 0.001 [7]. The working fluid used in the present study is lubricating oil 5W-30; it has a volumetric mass density $800 \mathrm{~kg} / \mathrm{m}^{3}$ and dynamic viscosity $0.008 \mathrm{~Pa} . \mathrm{s}$.

Fig. 4 shows the computed instantaneous torque acting on the pump rotor on the vertical axis versus rotor angle for 8 vane pump at $1500 \mathrm{rpm}$. The computed results show that as the pump rotor makes 6 complete rotations, the transient torque cycles become almost identical and the average torque reaches a steady-state value of 8.4 N.m.

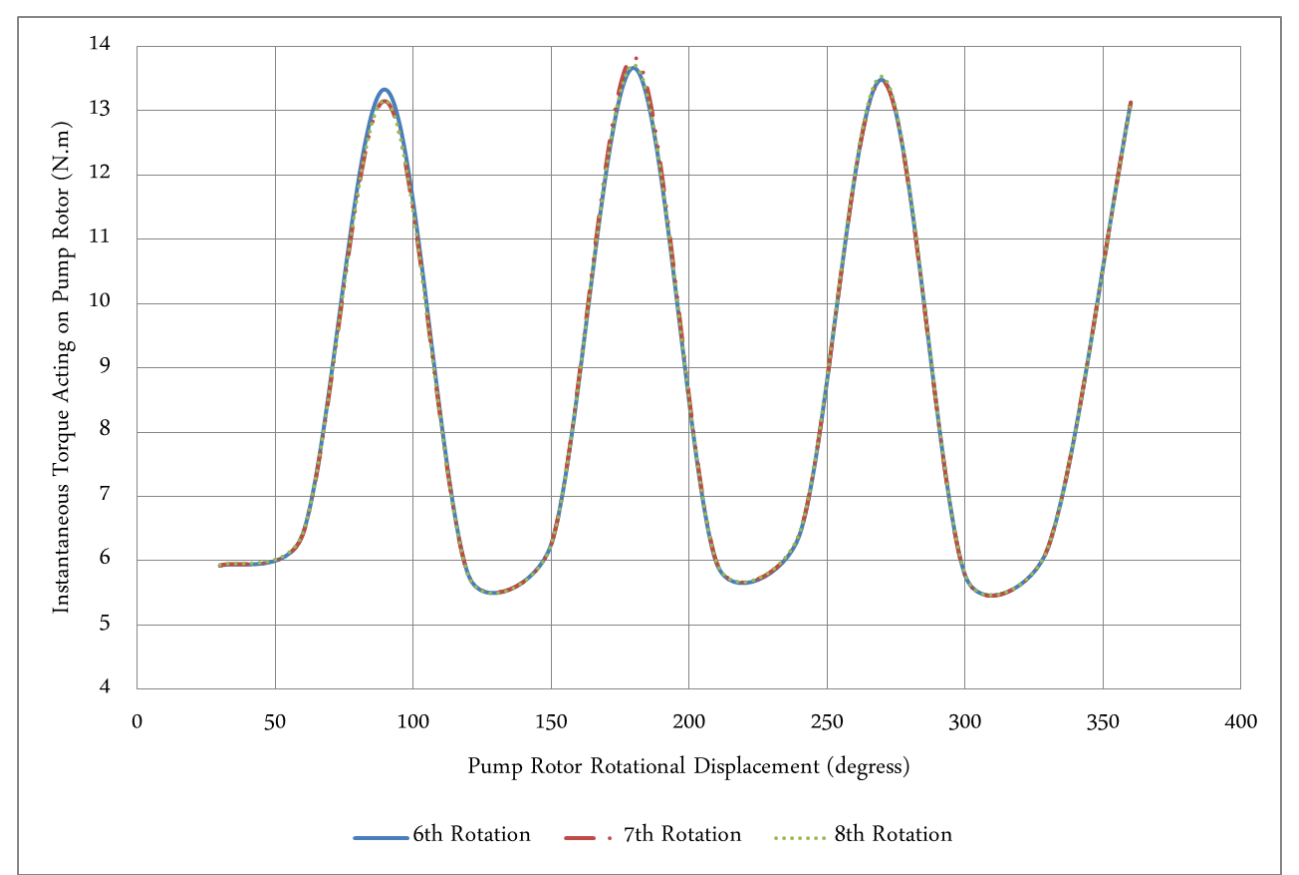

Fig. 4: Variation of Instantaneous Torque Acting on Pump Rotor with Rotation Angle for 8 Vane Pump at 1500 rpm 


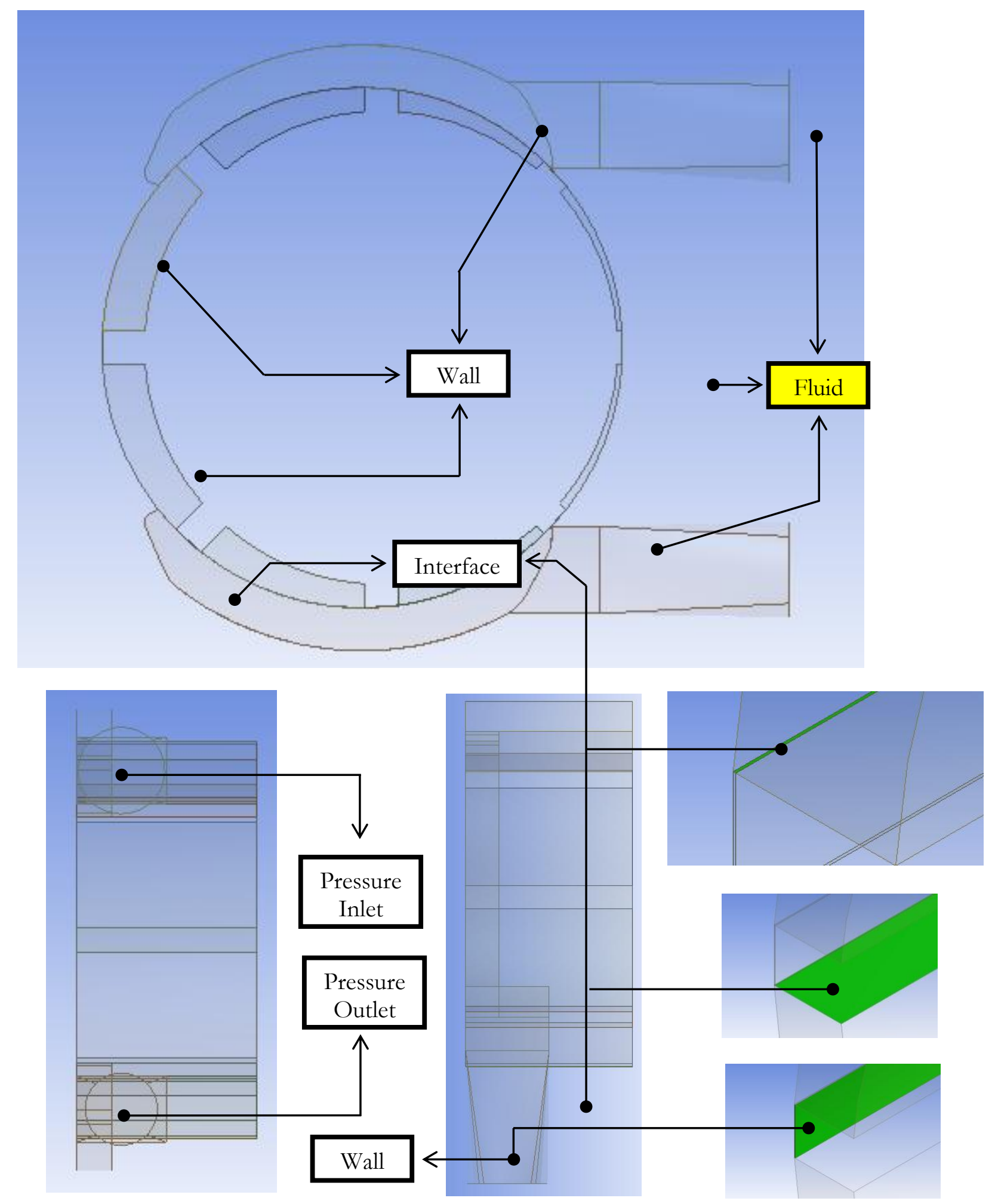

Fig. 3: Definition of Boundary Conditions of the Computational Domain 


\subsection{Computational Grid and Grid Independency Test}

There should not different solutions for different grid densities. In order to make sure that the numerical solution doesn't depend on the number of grid elements, a grid independency test has been first performed. Six different grid densities, 20000, 35000, 50000, 73000, 215000 and 500000 hybrid cells, as shown in Figs. 5 and 6, were examined. By comparing the values of the torque at the rotating shaft of the pump (the rotor) at different grid densities it can be shown that the effect of the number of hybrid grid cells is negligible and that a lower number of grid elements number, 125000 grid elements, can be safely used throughout the entire simulation process.
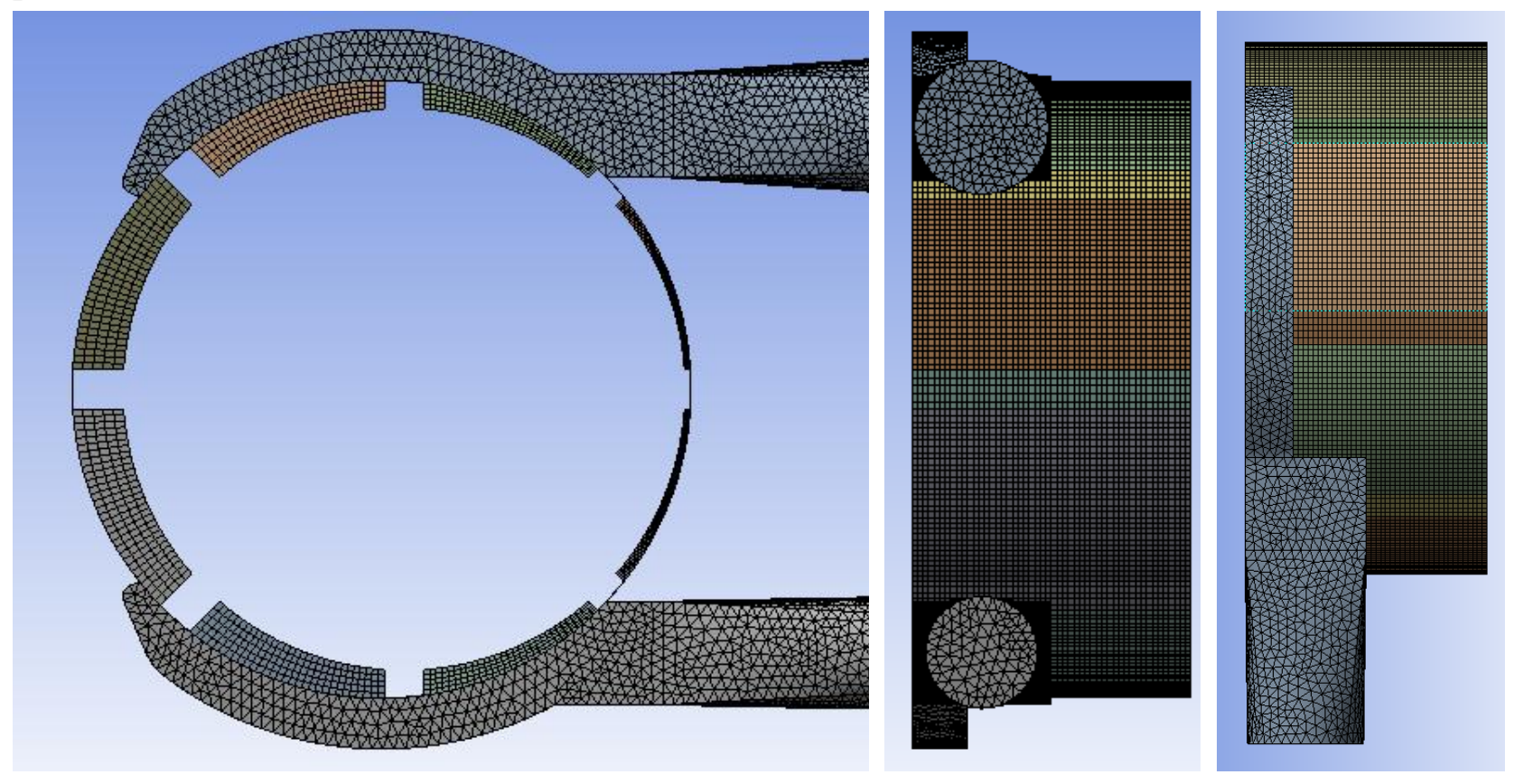

Fig. 5: Computational Grid for the Vane Pump Having Eight Vanes

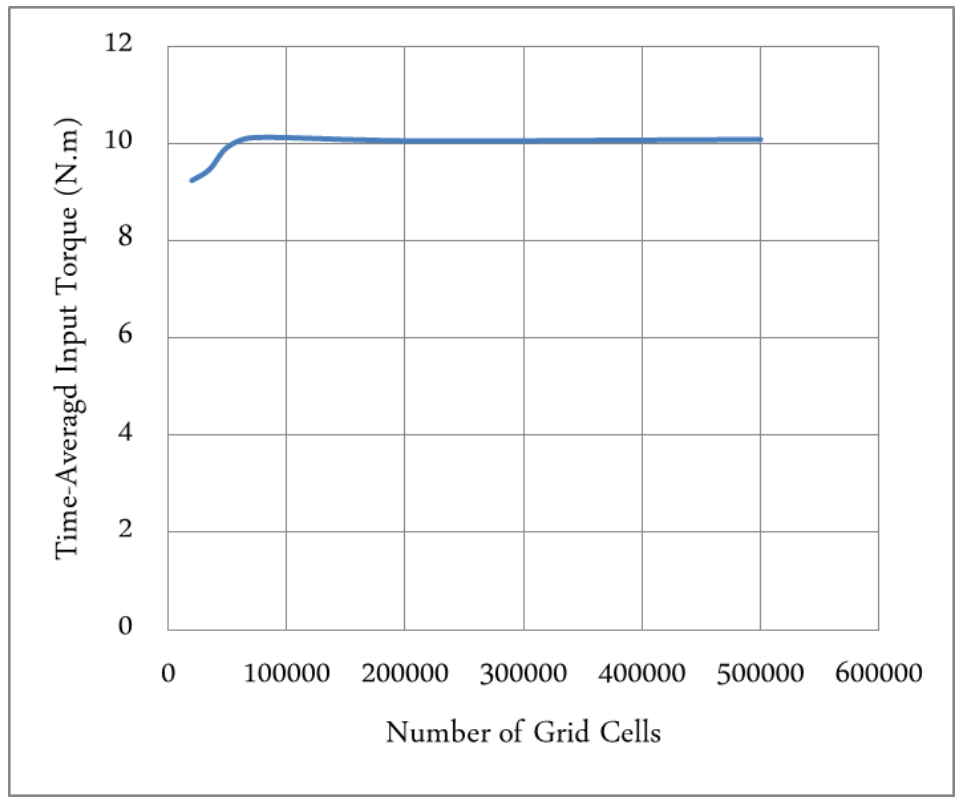

Fig. 6: Grid Independency Test for 8 Vane Pump at 1500 rpm 


\subsection{Time Step Size Test}

The effect of choosing a reasonable time step size on the solution time decides the required computational time. The time step size value should not be too small that the solution becomes very computationally expensive, or too large that the solution becomes inaccurate and unreliable. For this purpose, a time step size test was performed, at 0 bar gauge suction pressure at inlet, and 20 bar gauge discharge pressure at outlet, to know the optimum time step size that could be used. Time step sizes, $\Delta \mathrm{t}$, that will be used for the test correspond to rotational angle $2^{\circ}$, $1.5^{\circ}, 1^{\circ}$ and $0.5^{\circ}$. In each case, the number of revolutions must reach a periodic torque variation, Table 2. The time step size test shows that the maximum difference in the time-averaged torque acting on the pump rotor, $\mathrm{T}_{\mathrm{avg}}$., is $1.65 \%$, which is negligible considering the above mentioned four time step sizes. Furthermore, it is very noticeable that as the pump rotor reaches its $6^{\text {th }}$ cycle; the average torque reaches a steady-stage value of approximately $8.4 \mathrm{~N} . \mathrm{m}$. Therefore, the time step size used for the current work is $2^{\circ}$.

Table 2: Time Step Size Test

\begin{tabular}{|c|c|c|c|c|}
\hline Time-averaged Torque Acting on Pump Rotor, $\mathbf{T}_{\text {axg. }}$ \\
\hline \multirow{2}{*}{$\begin{array}{c}\text { Complete } \\
\text { Revolution Number }\end{array}$} & $2^{\circ}$ & $\mathbf{1 . 5 ^ { \circ }}$ & $\mathbf{1}^{\circ}$ & $\mathbf{0 . 5 ^ { \circ }}$ \\
\cline { 2 - 5 } & & & & \\
\hline Revolution 1 & 8.388 & 8.406 & 8.413 & 8.519 \\
\hline Revolution 2 & 8.366 & 8.393 & 8.420 & 8.525 \\
\hline Revolution 3 & 8.369 & 8.387 & 8.417 & 8.523 \\
\hline Revolution 4 & 8.364 & 8.382 & 8.404 & 8.533 \\
\hline Revolution 5 & 8.347 & 8.411 & 8.447 & 8.508 \\
\hline Revolution 6 & 8.373 & 8.410 & 8.456 & 8.505 \\
\hline Revolution 7 & 8.383 & 8.413 & 8.453 & 8.486 \\
\hline Revolution 8 & 8.383 & 8.410 & 8.456 & 8.505 \\
\hline
\end{tabular}

\subsection{Model Validation}

CFD models must be validated before they are used. It is never reliable to blindly use a CFD model without having been validated by comparing the numerical results with available experimental measurements. In this part of the study, the numerical model is by comparison with the experimental data depicted by $\mathrm{Oh}$ et al. [8]. The comparison is based on pump overall efficiency, noverall. Oil has been used as the working fluid with a temperature of $80^{\circ} \mathrm{C}$ resulting in a dynamic viscosity of $0.0066 \mathrm{~Pa}$.s, while the dynamic viscosity of the oil used in the current research is $0.008 \mathrm{~Pa}$.s. Moreover, the previous research used a clearance gap size value of 0.0675 $\mathrm{mm}$ which is slightly less than the clearance gap size used in the current study of $0.075 \mathrm{~mm}$. In addition, the previous work used a number of vanes of 9, while in the current research 8 vanes were used in the pump. Fig. 7 shows the comparison between current results and those of Oh et al at different pump speeds. It is shown that the overall efficiency for the present work and the previous work are very close for lower values of rotational speeds, with a minimum deviation of $1.8 \%$ at a $2000 \mathrm{rpm}$. Maximum deviation is $7.6 \%$ can be seen at $3000 \mathrm{rpm}$. The results show that the numerical model can be used with confidence to study pump performance. 


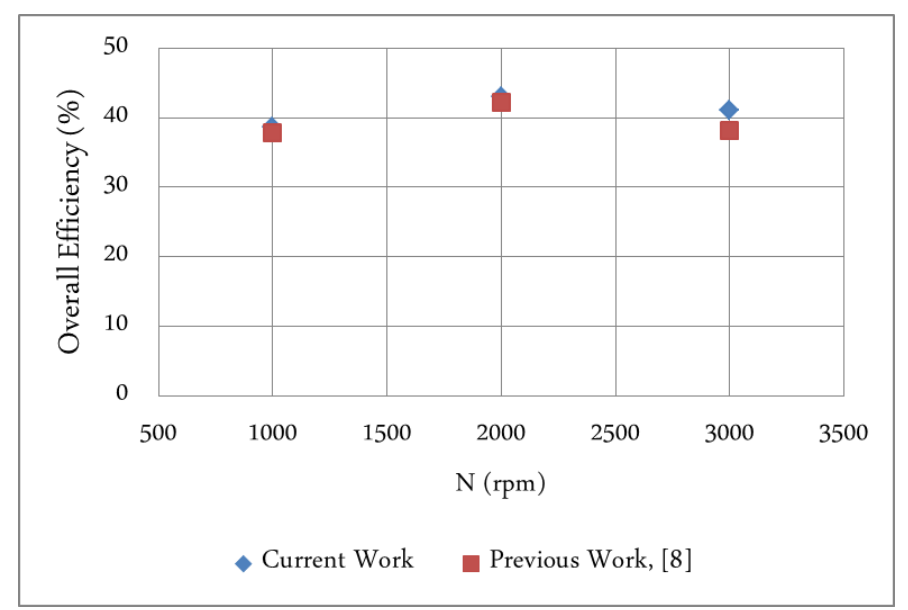

Fig. 7: Comparison between the Overall Efficiency for the Current Work and Previous Work, [8]

\section{SULTS AND DISCUSSION \\ 3.1 Pressure Contours}

Pressure contours of 4 vane pump are shown in Figs. 8 and 9. The gradient of pressure contours is very visible due to the small number of pump vanes. The zone near the suction port has suction pressure while that at the discharge port has discharge pressure. The fluid volume in between has an intermediate pressure between both pressures. The variation of the pressure gradient at the down-most gap within the pump is shown; as the oil fully finishes discharging through the discharge port, some residual oil stays and is swept by the vanes to the suction part of the pump. It can be seen how the pressure changes at the down-most gap, as the residual oil starts to occupy a larger volume before the suction phase in the next revolution starts. Two vanes are subjected to high pressure differential while the other two vanes are subjected to low pressure differential. This explains the oscillating nature of the torque required to drive the pump observed in Fig. 4.

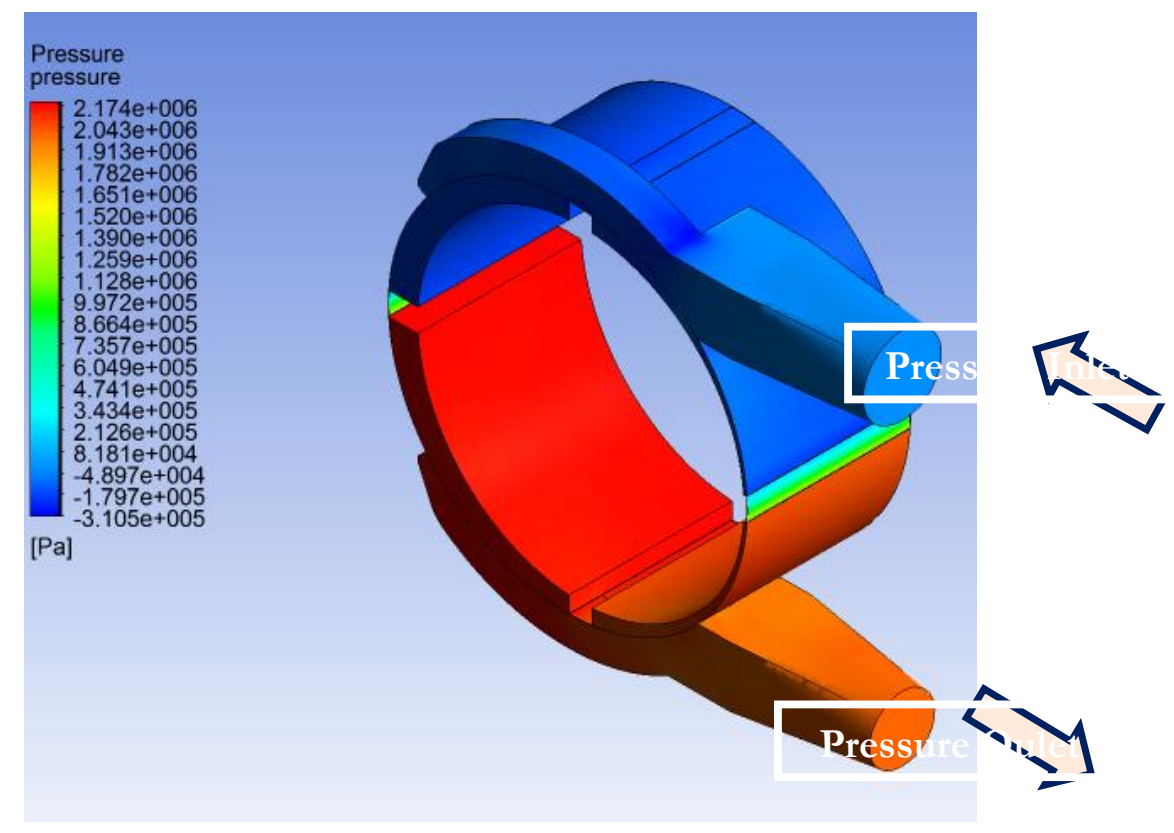

Fig 8: 3D Pressure Contours at a Rotational Speed of 3000 rpm, for a Four-Vane Pump 


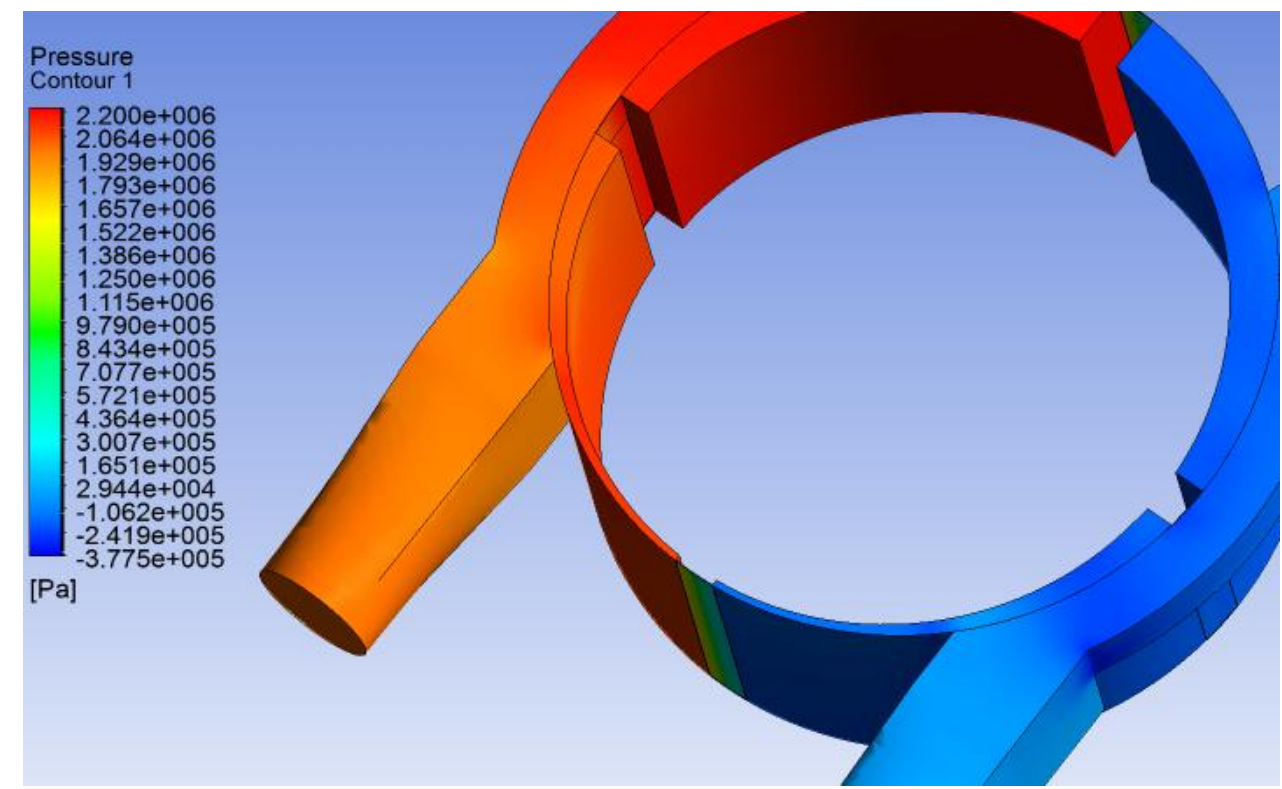

Fig 9: 3D Pressure Contours at a Rotational Speed of 3000 rpm, Focusing on the Discharge Side

Fig. 10 shows a comparison of the pressure contours for 4 vane, 6 vane and 8 vane pump cases. The pressure contours are shown at 4 different rotor angles $0,30,60$ and 90 degrees. Figs. a1-a4 correspond to 4 vane pump, Figs. B1-b4 correspond to 6 vanes case Figs. c1-c4 correspond to 8 vanes case. The figures show that as the number of vanes increases pressure gradient inside the flow passage is more pronounced. This indicates that the pressure rise is distributed over a higher number of vanes for pumps with more vanes. For 8 vane pumps the discharge pressure acts on the last vanes at all angles of the rotor.

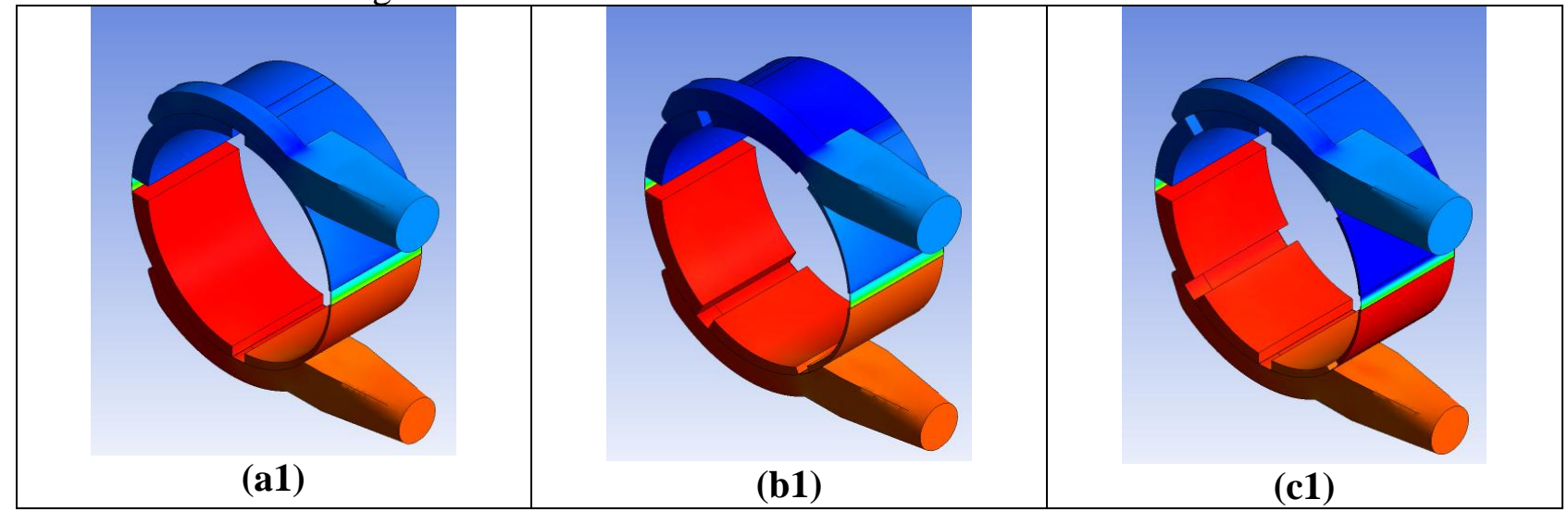




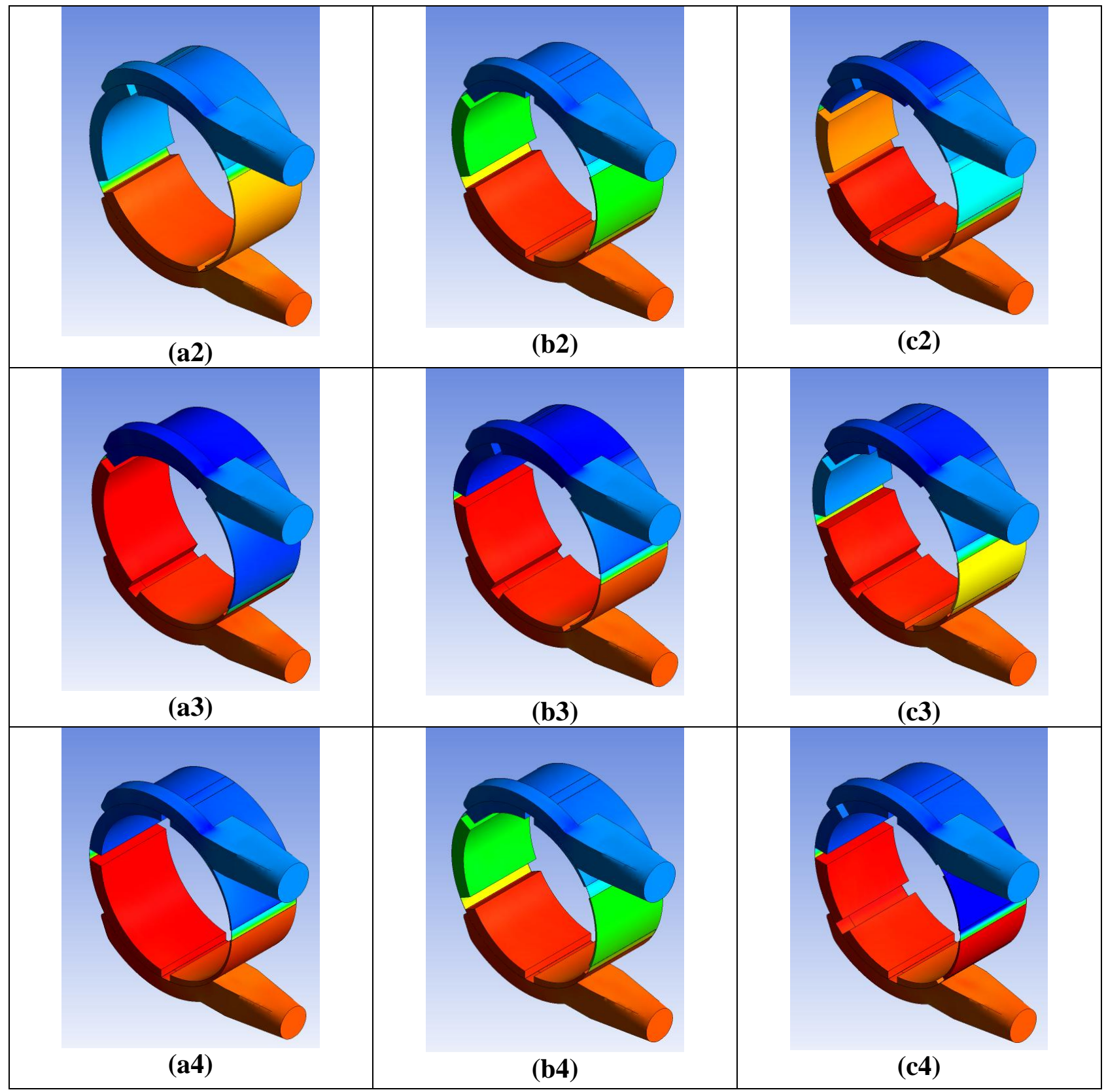

Fig 10: 3D Pressure Contours at a Rotational Speed of $3000 \mathrm{rpm}$ after $30^{\circ}$ Increment Rotation (a) Four-Vane Pump at $\theta=0^{\circ}, 30,60$ and 90 (b) Six-Vane Pump at $\theta=0^{\circ}, 30,60$ and 90 (c) Eight-Vane Pump at $\theta=0^{\circ}, 30,60$ and 90

\subsection{Velocity Contours, Streamlines and Velocity Vectors}

As the working fluid is admitted to the pump through the inlet port, the streamlines of the flow get closer to each other, since at this part of the suction port the area available for the fluid to flow is smaller and consequently it can be shown that the flow velocity at this part of the port increases, as shown in Figs. 11 through 18 which illustrate the streamlines of the flow as it enters from the inlet port at suction side to the cavity of the pump.

Moreover, as shown in Fig. 11 and Fig. 12, at the location of the suction and discharge ports where the area available for the flow of the oil decreases the streamlines and the velocity 
vector come closer to each other, and the magnitude of the velocity increases in value. The 3D velocity vectors come to a rest each time their flow path faces the obstacle of a rotating vane.

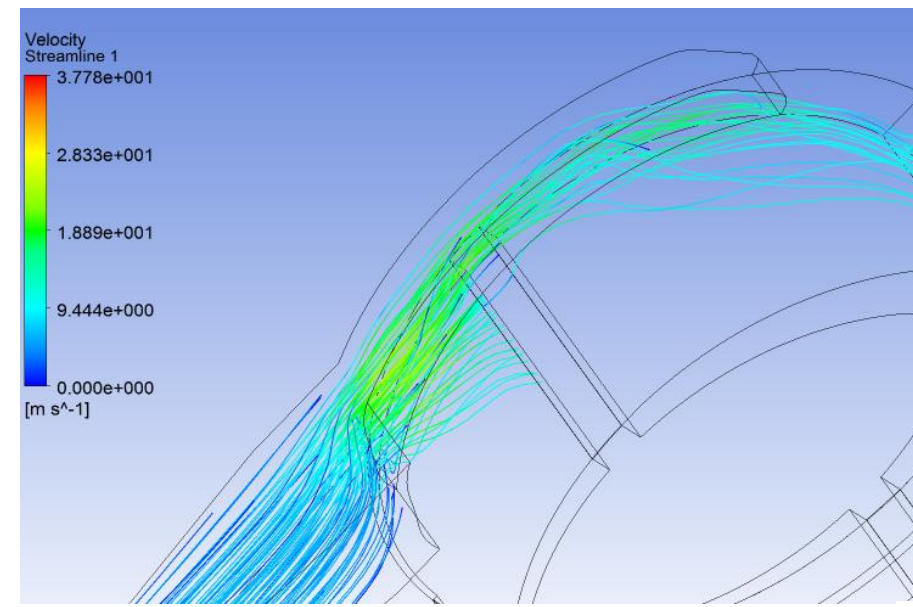

Fig. 11: A Close-up 3D View of Streamlines of Working Fluid Entering the Pump through the Inlet Port at Suction Side

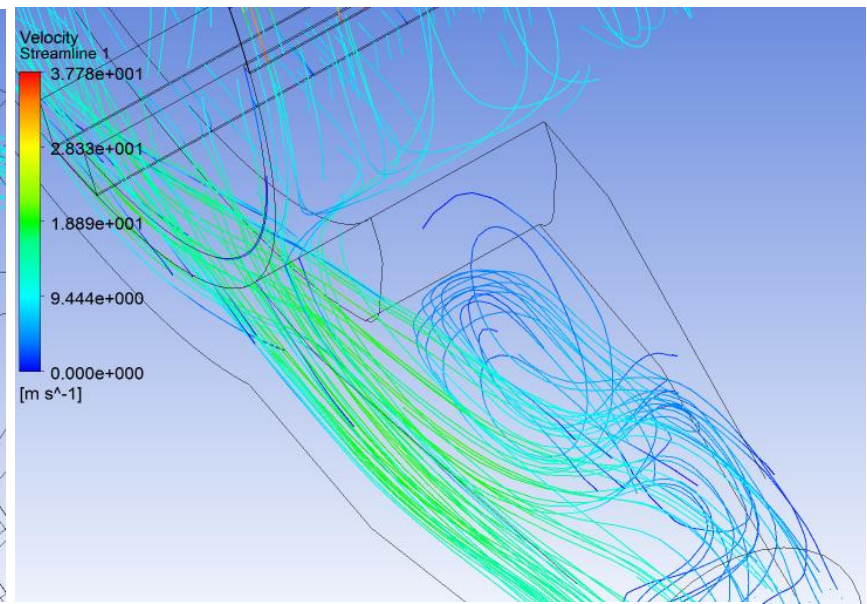

Fig. 12: A Close-up 3D View of Streamlines of

Working Fluid Entering the Pump through the Outlet Port at Discharge Side

The velocity vector field is illustrated in Figs. 13-15. The highest velocity is observed in the area between suction and discharge ports. Compressed fluid at the discharge port expands through the gap between the vane and the stator passing the discharge port. Pressure difference across this gap is the full pump pressure and leakage flow is highly accelerated to cause loss of this pressure. Therefore, it is important to maintain very low clearance gap in this area in order to prevent leakage from discharge port to suction port.

Near the discharge port, flow is collected at the narrow part of the discharge port causing an increase in velocity close to the location where a sudden expansion in the port is present. It can be further noticed that the lower half of the discharge port contains the fluid with higher velocity than the that observed at the upper half, and that is because at the lower half the centrifugal effect of the discharging fluid, when it is swept by the vanes rotating at a high rotational speed makes the fluid flows with a high inertia which spreads forward as the fluid is transported out of the pump.

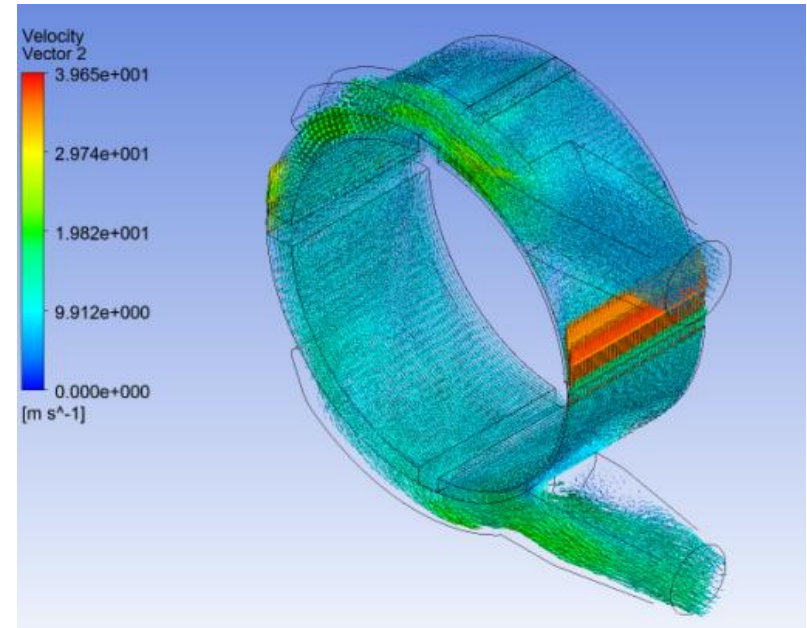

Fig. 13: 3D Velocity Distribution as a Vector Field within the Pump - N= $3000 \mathrm{rpm}$ 


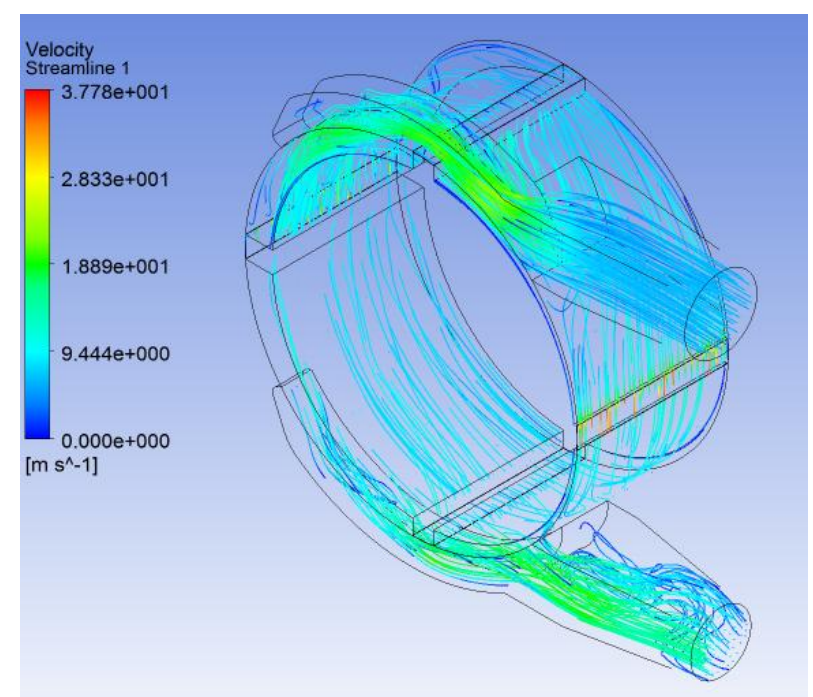

Fig. 14: 3D View of the Streamlines within the Pump - N= $3000 \mathrm{rpm}$

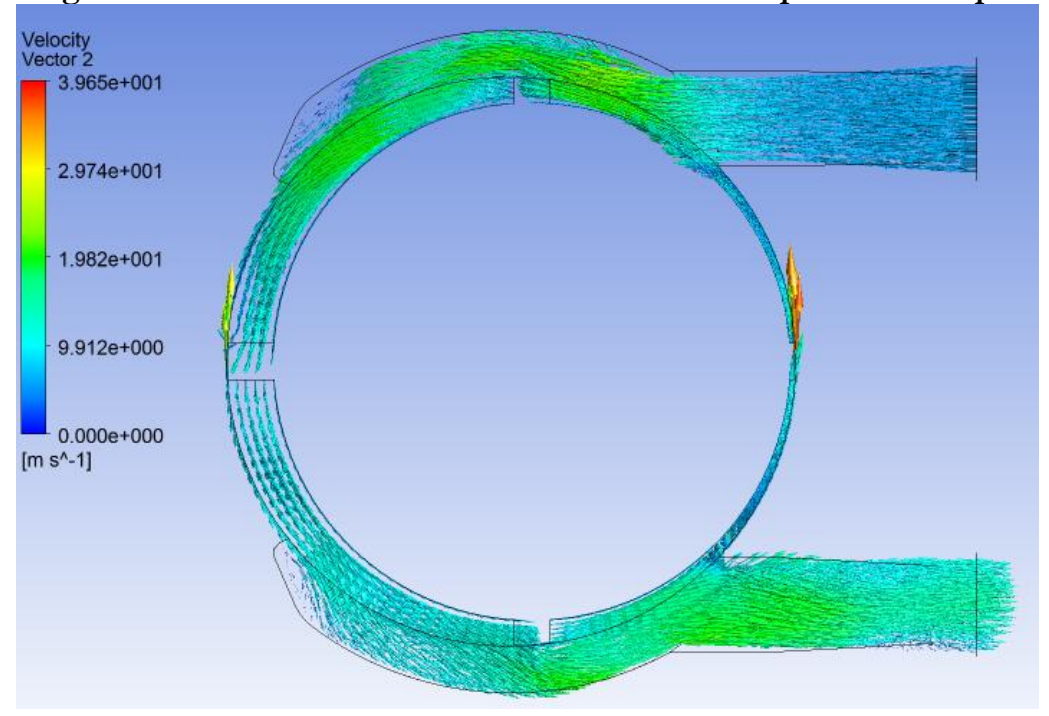

Fig. 15: 2D Velocity Distribution as a Vector Field within the Pump - N=3000 rpm

It is shown in Fig. 16 that as the upcoming oil flow moves to the narrow part of the suction port its velocity increase immensely, and further rotation of the rotor causes the oil to start entering the cavity generated by the vanes makes the velocity drop a little, yet it is still higher than while the flow was taking place in the wide part of the suction flow. Moreover, Fig. 17 shows that because of the presence of a narrow part of the discharge port, the velocity in it increases, and that immediately after the oil moves to the wide part of the discharge port its velocity drops. Recirculating flow is clearly present in the vicinity adjacent to the location where the area available for the flow suddenly increases. 


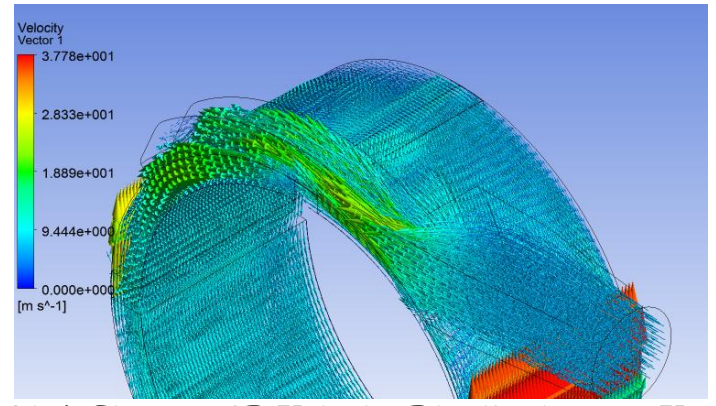

Fig. 16: A Close-up 3D Velocity Distribution as a Vector Field at the Inlet Port at Suction Side while Rotating at $3000 \mathrm{rpm}$

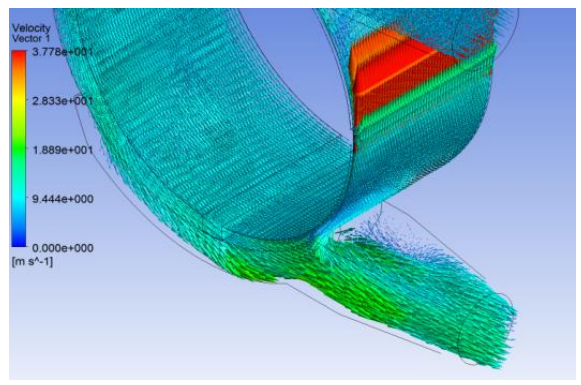

Fig. 17: A Close-up 3D Velocity Distribution as a Vector Field at the Outlet Port at Discharge Side while Rotating at $3000 \mathrm{rpm}$

In addition, Fig. 18, illustrates a visual representation of the formation of eddies due to the flow from a narrower flow passage to a wider flow passage in the outlet port at the discharge side. As the oil just flows out from the narrow passage, it further penetrates its way in the wider passage because of its inertia, at this instant, a volume of negative pressure value is generated (encircled zone) which causes a portion of the flowing oil to recirculate to this zone, wake flow, due to the difference of pressure which acts as the potential for this flow. When the flow was taking place in the vicinity of the narrow part of the discharge port its velocity was higher than when the sudden expansion occurred. Recirculating flow present in the wake zone acts as a disadvantage of this certain rotary sliding vane pump design, and would cause a decrease in the hydraulic efficiency and fluid power. Thus, better design concepts should be implemented to eliminate, or at least reduce, this geometrical drawback of sudden expansion which is the cause for such interior circulating wake flow.

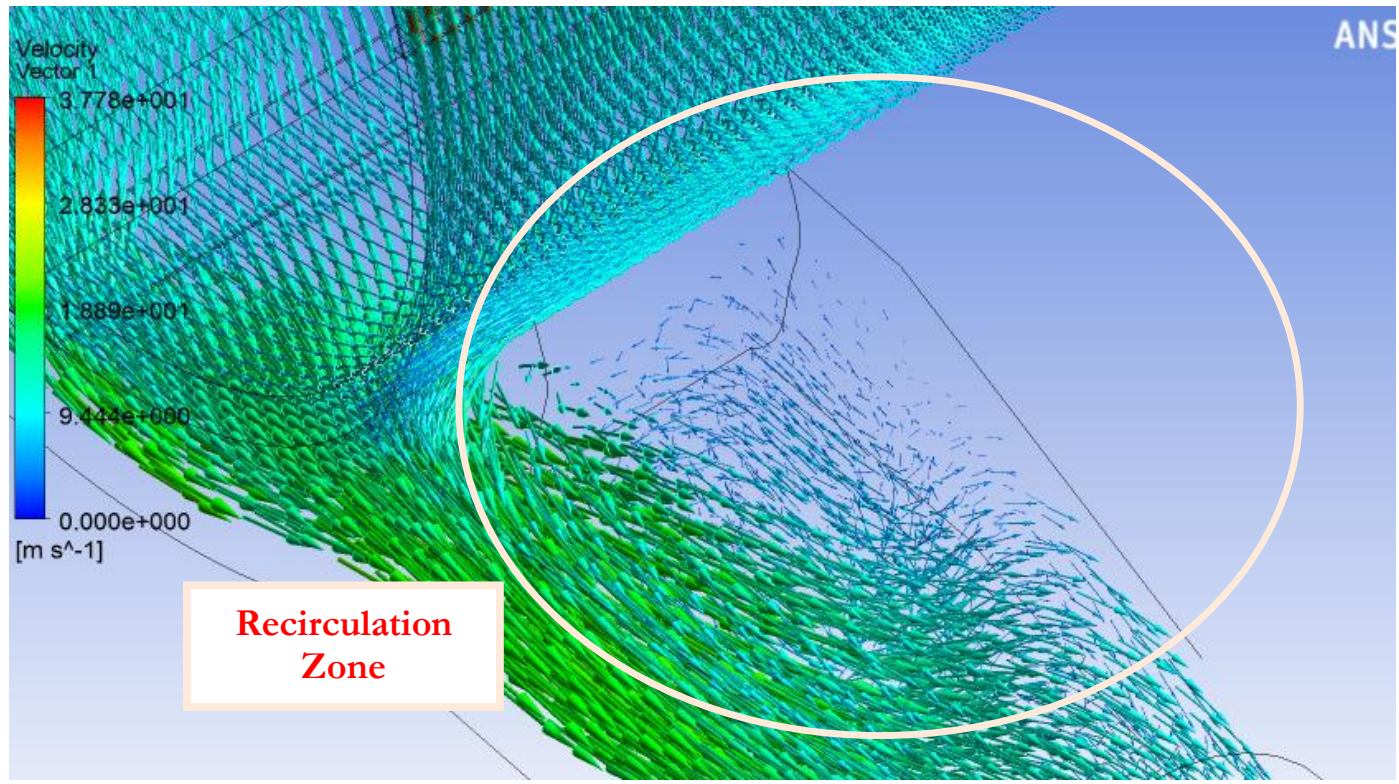

Fig. 18: Wakes Formation at the Expanding Section-N=3000 rpm

Fig. 19 compares the 2D velocity contours of 4, 6 and 8 vane pump at different rotor angles of 0 , 30, 60 and 90 degrees. The velocity contours show similar acceleration pattern near the suction and discharge ports due to the pump geometric shape at these areas. Velocity inside the cavity 
formed between vanes and stator are translation velocity corresponding to rotor linear speed close to $15 \mathrm{~m} / \mathrm{s}$. Low velocity zones are observed near stationary surfaces. Large recirculation zones are also formed near the expanding region of the discharge and suction channels. The flow patterns are affected by the number of vanes. For 8 vane configuration small variations in the velocity pattern are observed due to the high number of vanes. Events are repeated due to vanes taking the same position very closely in time. For 4 vane pump the velocity contours are changing significantly as the rotor angle changes due to the low number of vanes. The vane swapping the suction port takes some time before another vane is approaching and this causes large recirculation zones near the suction port cavity.

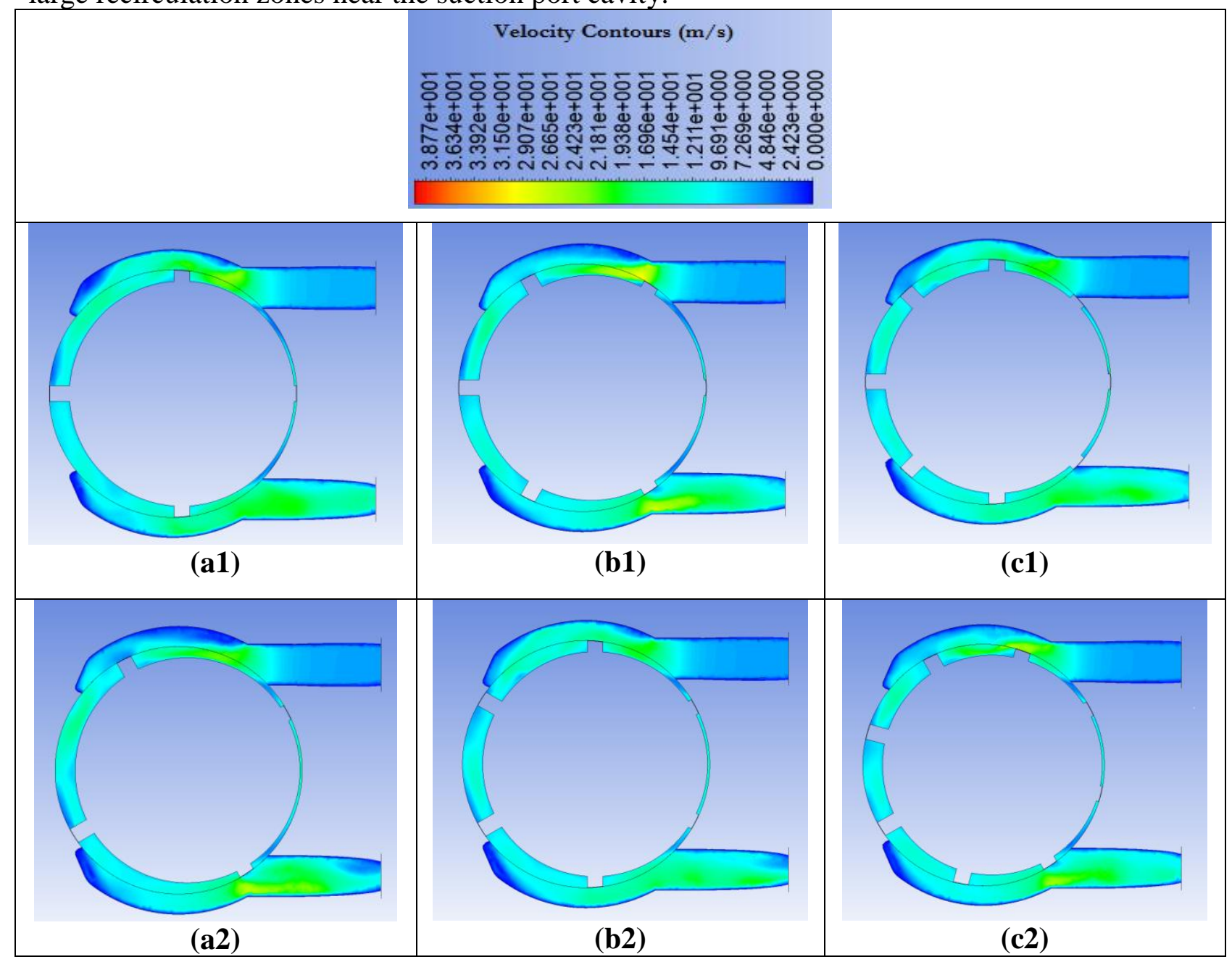




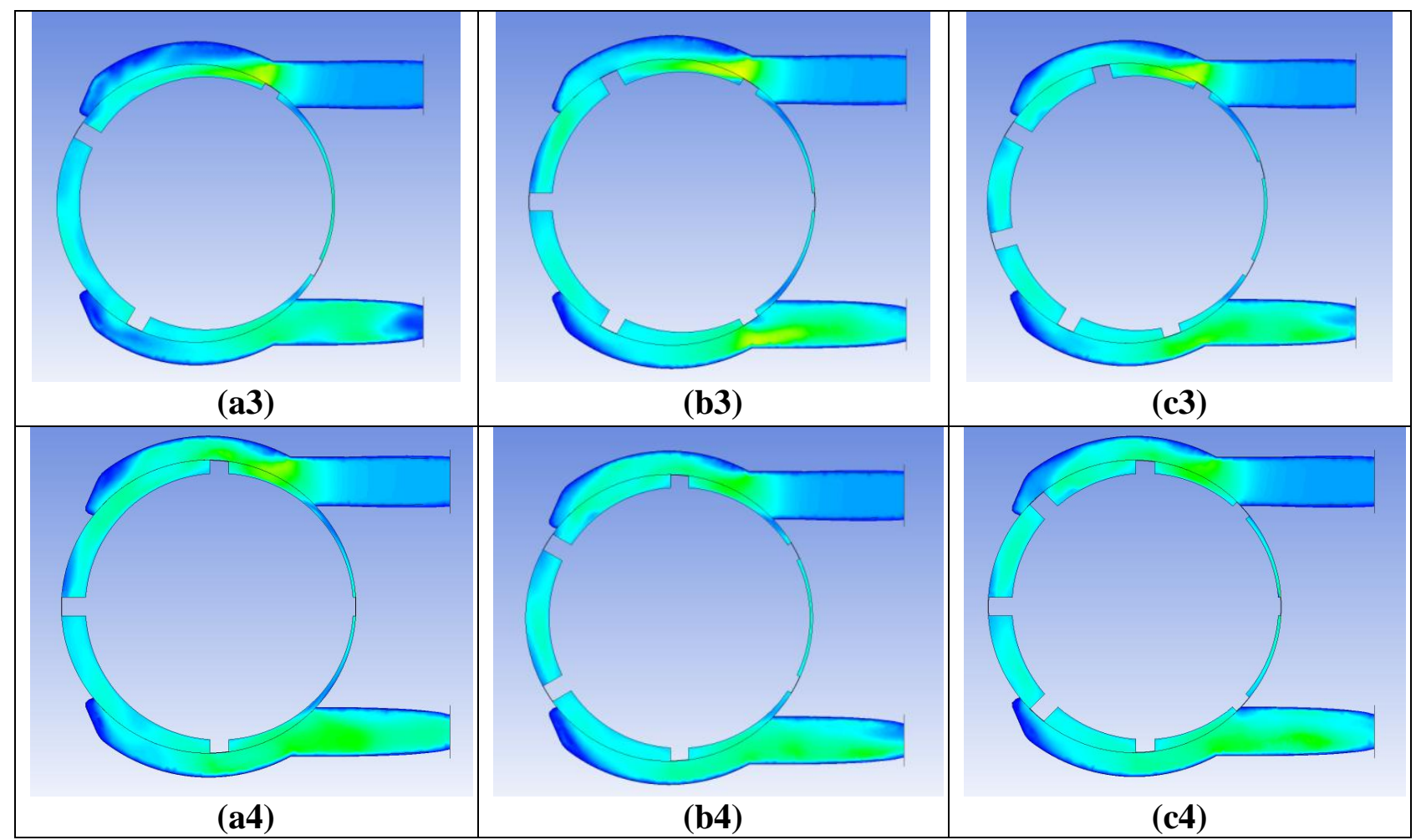

Fig 10: 3D Velocity Contours at a Rotational Speed of $3000 \mathrm{rpm}$ after $30^{\circ}$ Increment Rotation

(a) Four-Vane Pump at $\theta=0^{\circ}, 30,60$ and 90 (b) Six-Vane Pump at $\theta=0^{\circ}, 30,60$ and 90

(c)Eight-Vane Pump at $\theta=0^{\circ}, 30,60$ and 90

Fig. 20 shows the computed time-averaged torque acting on the rotary sliding vane pump for different number of vanes at different rotational speeds varying from $500 \mathrm{rpm}$ to $3000 \mathrm{rpm}$. The figure shows that the required torque increases as the number of vanes increases, to overcome the increase in resistive torque caused by higher frictional forces that accompany the increase of summation of vane tips surfaces when they come in relative motion with the inner surface of the stator. The effect of number of rotational speed corresponds to increasing flow rate and friction forces too and is non-linear

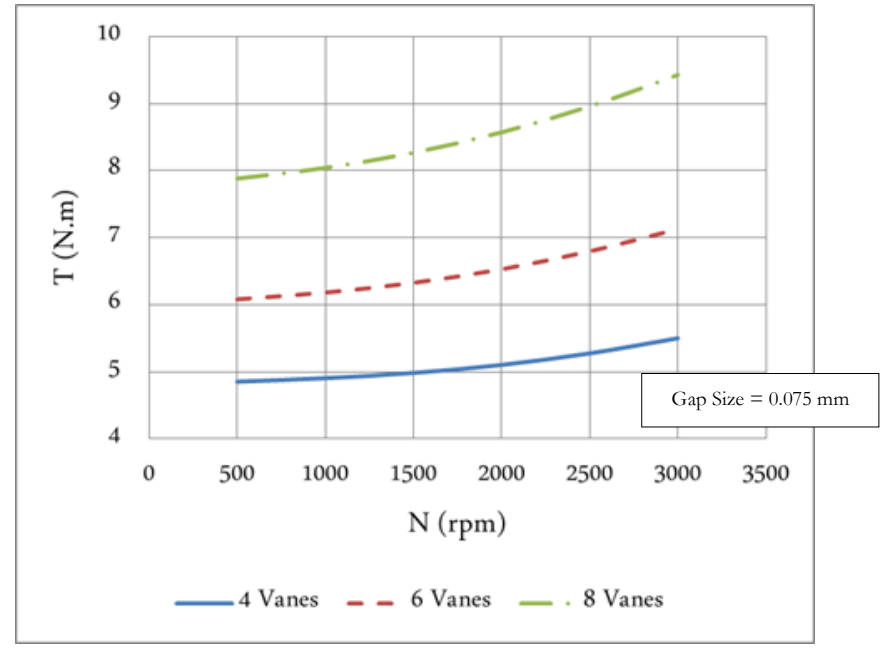

Fig. 20: Time-Averaged Torque Acting on Pump Rotor, for Different Number of Vanes 
Fig. 21 shows the computed variation of the dimensionless volume flow rate of the sliding vane pump decreases for different number of vanes too and different rotational speeds. The volumetric flow rate is normalized by the theoretical pump flow rate calculated from equation (1). Lower flow rates are observed for 8 vanes compared with 6 and 4 vane cases. This is attributed to the fact that more vanes occupy more volume which reduces the swept volume which, in turn, account for lower volume available for the working fluid to fill up. Another reason for the observed deviation between theoretical and computed flow rate is attributed for leakage flow between vanes and the stator. As pump speed increases, more flow is pumped while keeping approximately the same leakage flow rate which depends mainly on the pressure differential across the pump.

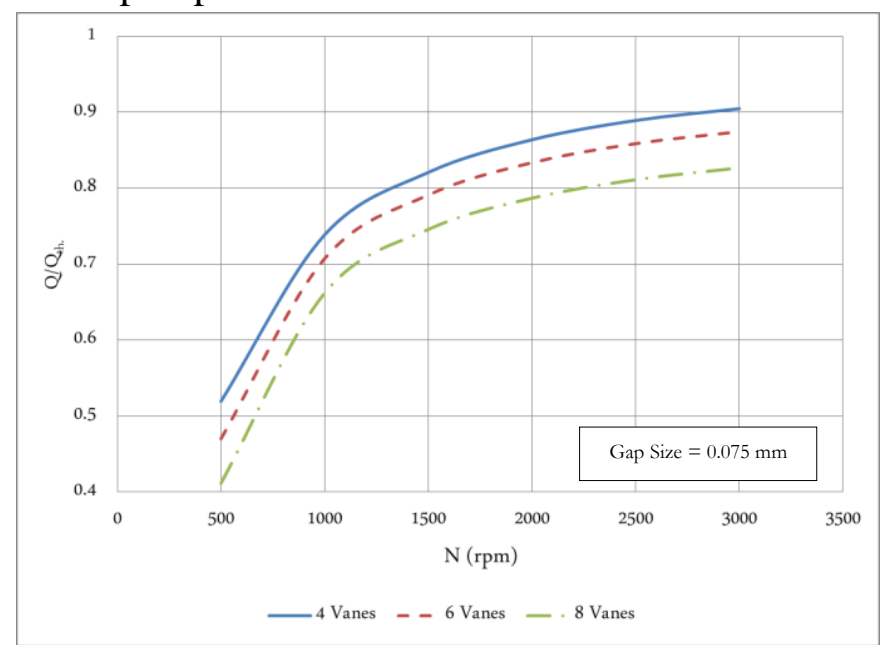

Fig. 21: Dimensionless Volume Flow Rate of the Pump, for Different Number of Vanes

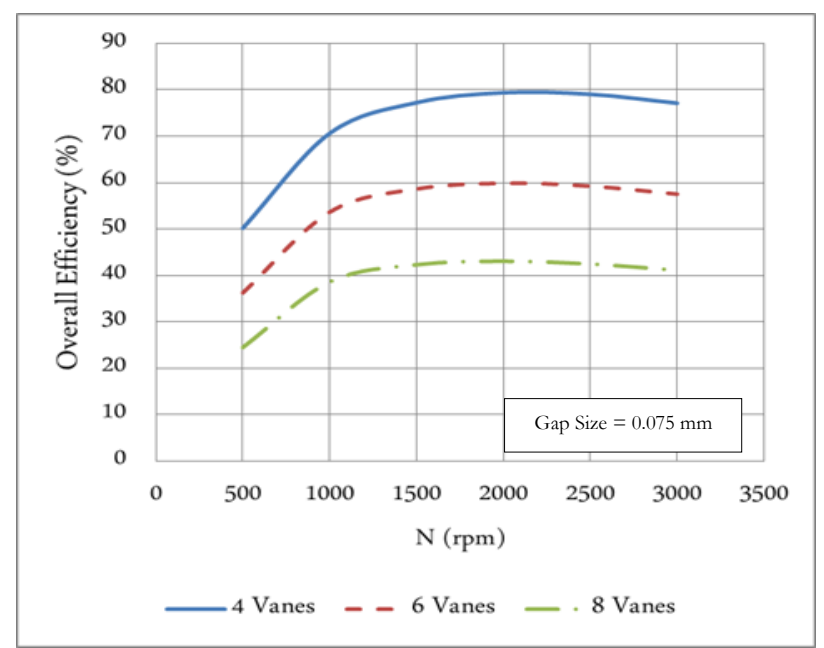

Fig. 22 Variation of pump Efficiency, for Different Number of Vanes

The size of the radial clearance gap has a large effect on the pump performance Figs. 2325 show the pressure contours within the gap between the vane tip and stator surface for radial clearance gap size of $0.025 \mathrm{~mm}, 0.05 \mathrm{~mm}$ and $0.075 \mathrm{~mm}$, respectively. Since similar pressure gradient exists in all gaps, the higher gap size will allow higher leakage flow.

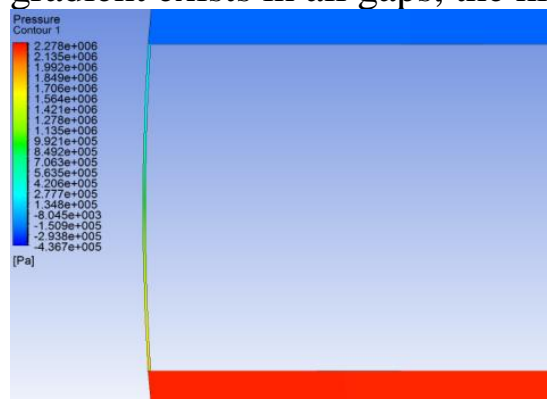

Fig. 23: Pressure Contours within a 0.025 mm Radial Clearance Gap

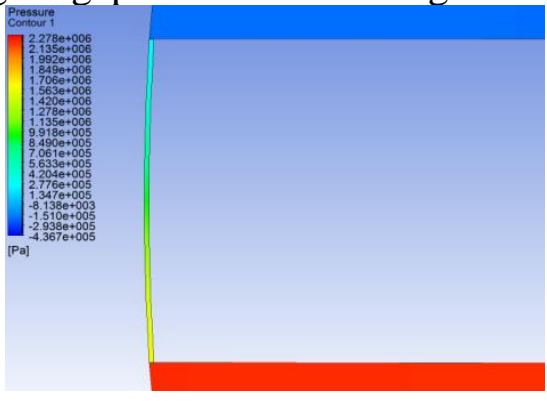

Fig. 24: Pressure Contours within a 0.05 mm Radial Clearance Gap

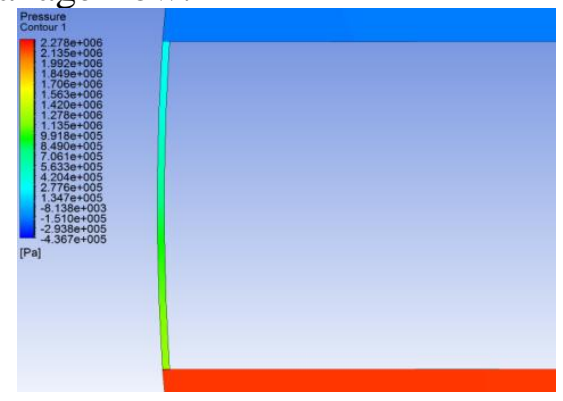

Fig. 25: Pressure Contours within a 0.075 mm Radial Clearance Gap Fig. 26 shows the computed time-averaged torque acting on the sliding vane pump for different gap sizes. The torque decreases with the increase of the radial clearance gap size. As the vanes tips move farther away from the inner surface of the stator, the friction between them decreases which reduces the resistive torque required to be overcome. This is due to higher shear rates which are formed in the gap flow when gap size decreases. 


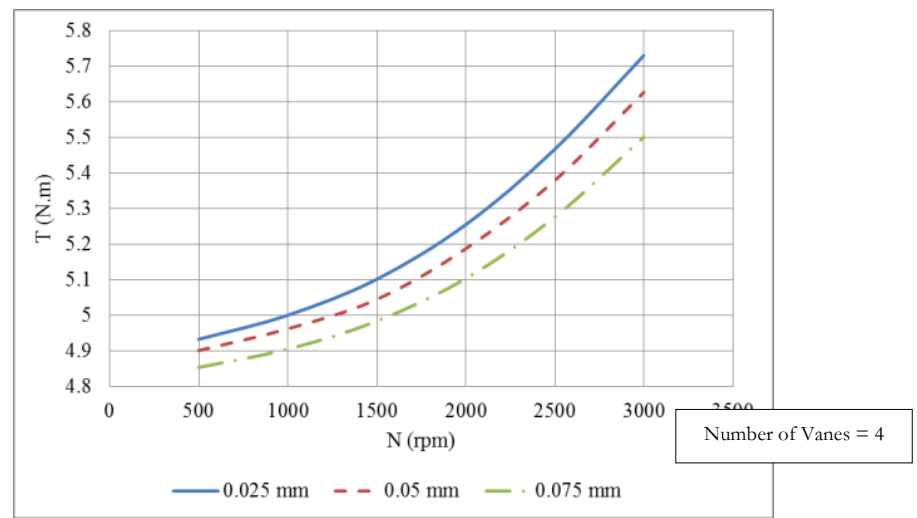

Fig. 26: Time-Averaged Torque Acting on Pump Rotor for Different Radial Clearance Gap Sizes

Fig. 27 illustrated that effect of gap size on the dimensionless volume flow rate of the sliding vane pump. As gap size decreases more leakage results in reduced flow rate, compared with theoretical flow rate. The reason for that is that with the increase in the volume above the tips of the vanes as the vanes move farther away from the stator, more working fluid leaks and flows over the vane tips, and doesn't discharge at the outlet.

Fig. 28 represents the overall efficiency variation with rotational speed for different radial clearance gap size. As the gap size increases, pump overall efficiency decreases. This is due to the observed decrease in flow rate as gap size increases. Although increasing the gap size reduces friction and therefore torque required, the reduced flow rate is more important and consequently gap size increase reduces overall efficiency.

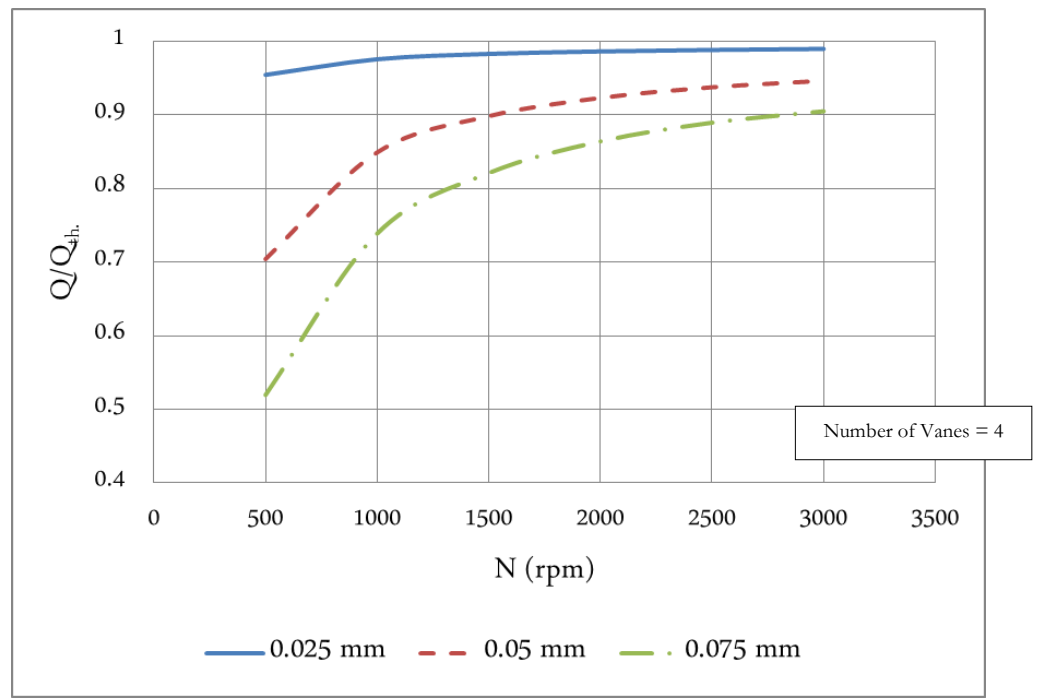

Fig. 27: Dimensionless Volume Flow Rate of the Pump for Different Radial Clearance Gap Sizes 


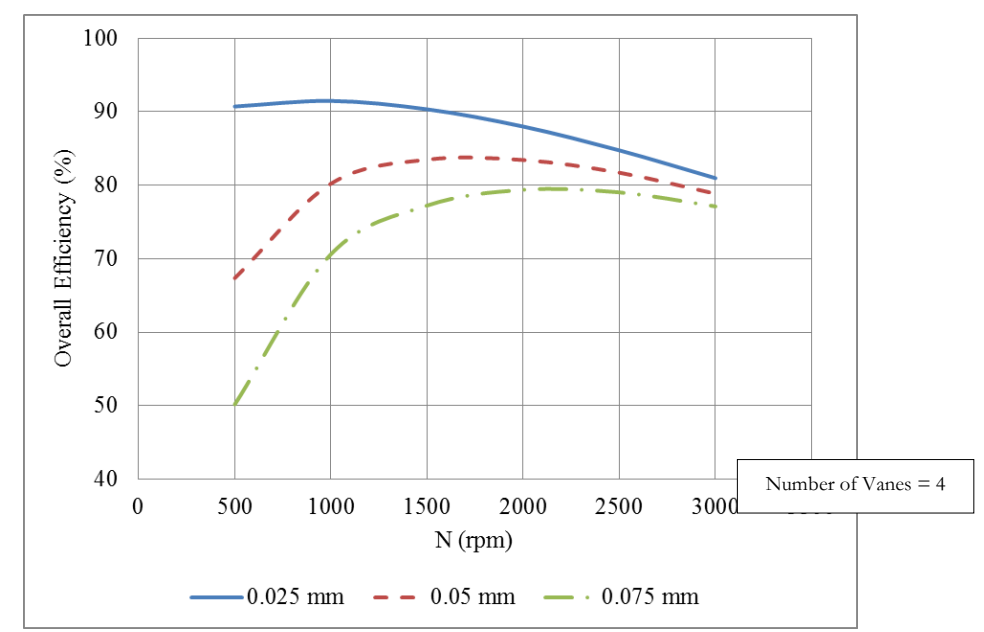

Fig. 28: Pump Overall Efficiency for Different Radial Clearance Gap Sizes

In addition, Fig. 29 represents the performance curves for the rotary sliding vane pump, at constant rotational speeds, showing the effect of slippage. Rotary sliding vane pumps, as well as all positive displacement pumps, deliver a definite volume of liquid for each cycle of pump operation. Therefore, the only factor that affects flow rate in an ideal positive displacement pump is the speed at which it operates. The flow resistance of the system in which the pump is operating will not affect the flow rate through the pump. It can be shown that as the discharge pressure of the pump increases, some amount of liquid will leak from the discharge side of the pump back to the pump suction side, reducing the effective flow rate of the pump.

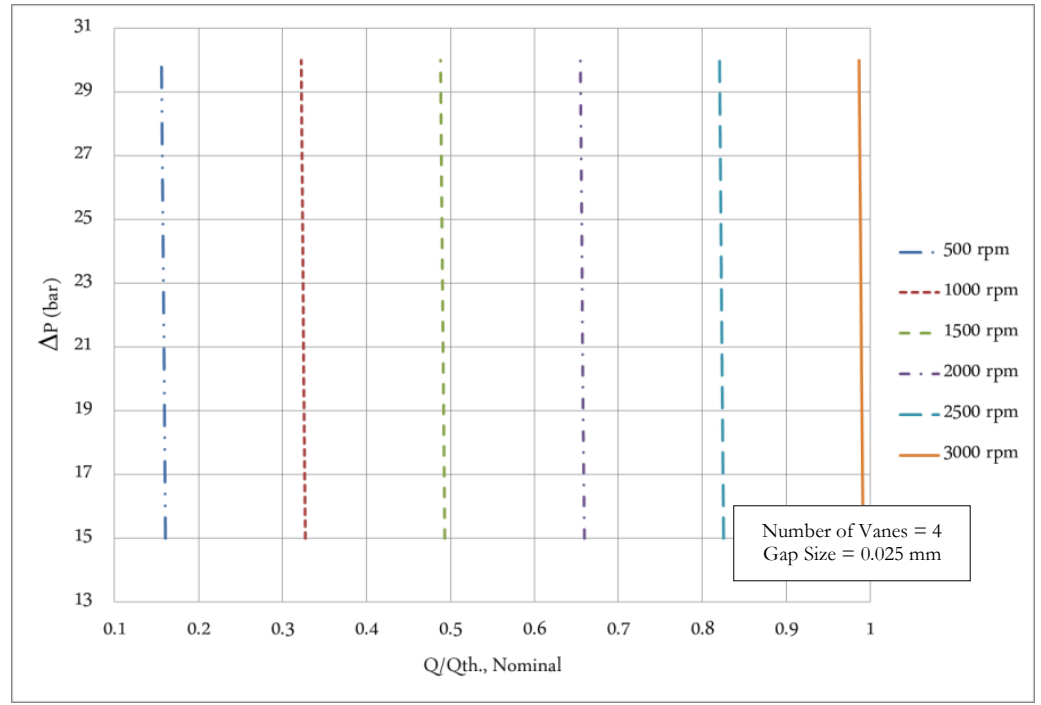

Fig. 30: Rotary Sliding Vane Pump Performance Curves for 8 vanes pump

\section{CONCLUSIONS}

The aim of this study is to examine the performance of rotary sliding vane pumps, using the tool of numerical modelling (CFD), for two design parameter cases, which are; the number of vanes: four vanes, six vanes and eight vanes and the radial clearance gap size: $0.025,0.05$ and $0.075 \mathrm{~mm}$ at six rotational speeds of: 500, 1000, 1500, 2000, 2500 and $3000 \mathrm{rpm}$. The working fluid is $5 \mathrm{~W}-$ 
30 internal combustion engine lubricating oil. The numerical model results have been validated by comparison of computed pump efficiency with experimental measurements which have shown good agreement.

It was found that, increasing the number of vanes from four to six results in a $27.52 \%$ increase in the time-averaged torque acting on the pump rotor, a $4.25 \%$ decrease in the dimensionless volume flow rate of the pump and $25 \%$ decrease in overall efficiency. Further increase of the number of vanes from six to eight has similar effect. As the radial clearance gap size increases from $0.025 \mathrm{~mm}$ to $0.05 \mathrm{~mm}$ has the result of a $1.22 \%$ decrease in the time-averaged torque acting on the pump rotor, a $10.52 \%$ decrease in the dimensionless volume flow rate of the pump and $9.72 \%$ decrease in the overall efficiency. Moreover, additional increase in the radial clearance gap size to $0.075 \mathrm{~mm}$ decreases the time-averaged torque acting on the pump rotor by $1.53 \%$, decreasing the dimensionless volume flow rate of the pump by $9.9 \%$, and decreases the overall efficiency by $8.73 \%$. The results show that it is required to observe the radial clearance gap since it has large effect on pump performance.

\section{REFERENCES}

[1] Chicurel-Uziel, R. "Single Vane Pumping Mechanism", 12 ${ }^{\text {th }}$ IFTOMM World Congress, Besancon, June 18-21, 2007.

[2] Elashmawy, M. and Alghamdi, A. "Vane Geometry Effect on Lubrication Conditions between Vane Tip and Cam-ring in Hydraulic Vane Machines", International Journal of Mechanical Engineering and Application; 3(1-2): 1-10. doi: 10.11648/j.ijmea.s.2015030102.11, ISSN: 2330-023X (Print); ISSN: 2330-0248 (Online), 2015.

[3] Lisowski, E. and Panek, M. "CFD Modelling of Vane Pump Vanes Operation", EKSPLOATACJA I NIEZAWODNOŚĆ NR 2/2004, 2004.

[4] Hain-Würtenberger, S. "Simulation of Cavitating Flow in Vane Pumps", European Automotive CFD Conference, 2007.

[5] Babu, J. M.; Mariappan, R.; Karthik, C.; VijayaKumar, K.; and Kumar, J. S. "Parametric Studies on Critical Parameters of Variable Displacement Oil Pump for Automotive Application", Applied Mechanics and Materials Vols. 592-594 pp 1697-1705, doi:10.4028/www.scientific.net/AMM.592-594.1697, 2014.

[6] Meece, W.; Blank, O.; and Ickes, C. W. "Design of Oil-less Compressors and Pumps", International Compressor Engineering Conference Paper 129, School of Mechanical Engineering, http://docs.lib.purdue.edu/icec/129, 1974.

[7] "Vane Pump Modeling in ANSYS FLUENT Release 13.0", FLUENT-MDM-tut06_vane-pump, ANSYS, Inc. 2010.

[8] Oh, J. K.; Moon, H. B.; and Cho, H. "Theoretical Study on Performance Characteristics of a Variable Displacement Vane Pump According to a Variable Amount Occurrence", Journal of Mechanical Science and Technology 29 (9) (2015) 3717 3726, DOI 10.1007/s12206-015-0817-3, www.springerlink.com/content/1738-494x(Print)/19763824 (Online), 2015.

[9] Peng, Y.; Chen, X.; Cao, Y.; and Hou, G. "Numerical Study of Cavitation on the Surface of the Guide Vane in Three Gorges Hydropower Unit", Journal of Hydrodynamics, 22 (5) 703-708, 2010.

[10] Emiliano, M.; Alessandro, A.; Gianluca, D.; and Giorgio, D. "On the Ware and Lubrication Regime in Variable Vane Pump", Wear, 306 (1-2) 36-46, 2013.

[11] Kim, C. S.; Bae, C. Y.; Kim C. J.; Kim, K. S.; and Son, T. S. "Experimental Research on the Power Saving Effect Evaluation of a Variable Displacement Vane Pump for an Automatic Transmission", Journal of KSAE, 22 (7) 1-7, 2014.

[12] Ueno, H.; Shintani, R. and Okazima, A. "Pressure and Flow Ripples of a Variable Displacement Vane Pump”, Journal of JSME, 53 (490) 1742-1749, 1986. 